\title{
Etiologies of Non-Genetic Epilepsies of Adults Newly Diagnostic in Ouagadougou in Burkina Faso
}

\author{
Lompo Djingri Labodi ${ }^{1 *}$, Cisse Kadari², Dao Ben Aziz ${ }^{3}$, Diallo Ousseini ${ }^{3}$, Ouro Sia Aida ${ }^{1}$, Millogo Athanase ${ }^{4}$
}

${ }_{1}^{1}$ Tingandogo University Hospital, Health Sciences Research and Training Unit (UFR/SDS), Ouaga University I-Pr Joseph Ki-Zerbo, Ouagadougou, Burkina Faso ${ }^{2}$ Department of Medical Biology and Public Health, Ouagadougou Institute for Health Sciences, Ouagadougou, Burkina Faso

${ }^{3}$ Yalgado Ouedraogo Teaching Hospital of Ouagadougou, UFR/SDS, University of Ouagadougou, I-Pr Joseph Ki-Zerbo, Ouagadougou, Burkina Faso

${ }^{4}$ Suro Sanou Hospital of Bobo-Dioulasso, UFR/SDS, Ouaga University I-Pr Joseph Ki-Zerbo, Ouagadougou, Burkina Faso

\begin{abstract}
Introduction: Epilepsy is a common disease in sub-Saharan Africa. The etiological diagnosis of epilepsies is still based on interrogation and clinical examination, due to a lack of means of complementary diagnostic investigations, electroencephalogram (EEG), computed tomography (CT) or magnetic resonance imaging (MRI). The aim of our study was to determine the etiological varieties of non-genetic epilepsies of adults, newly diagnosed in Ouagadougou, according to diagnostic, clinical, EEG and neuroradiological criteria (encephalic CT and/or MRI).
\end{abstract}

Patients and methods: This was a prospective, cross-sectional, descriptive study that ran from September 1 to August 31, 2017, and included patients diagnosed with non-genetic epilepsy in adults, newly diagnosed in Ouagadougou, Burkina Faso. For each of the patients included in the study, the etiological diagnosis was based on the results of CT and /or brain MRI, in addition to the electroclinical criteria of non-genetic epilepsy.

Results: We collected 137 patients; the average age was $41.8 \pm 17.6$ years, with $51.8 \%$ men (71 patients). The average age of onset of seizures was 34.3 years and the average duration of seizures was 7.3 years. Of all patients, $87.5 \%$ had focal seizures, $5.2 \%$ generalized seizures and $7.3 \%$ non-classifiable seizures. All of our patients had EEG and brain scan, only $11.8 \%$ had brain MRI. EEG was normal in $13.1 \%$; there were inter-critical epileptic paroxysms in $86.9 \%$. Localized atrophy associated with underlying parenchymal hypodensity with 48 cases $(35 \%)$, porencephalic cavities with 16 cases $(11.8 \%)$, circumscribed cortico-subcortical hypodense without contrast enhancement with 14 cases $(10.2 \%)$, brain tumors with 12 cases $(8.8 \%)$, were the most representative neuroradiological abnormalities. The structural causes and unknown causes were found respectively in $54 \%$ and in $46 \%$ of cases. CNS infections (16.8\%), sequelae of stroke $(11.7 \%)$, sequelae of cranioencephalic trauma $(10.9 \%)$, brain tumors $(8.7 \%)$, sequelae of Perinatal encephalopathy $(4 \%)$ and cerebral vascular malformations (cavernoma) $(1.5 \%)$ were the epileptogenic structural abnormalities found.

Conclusion: Our results confirm the predominance of infectious and post-traumatic causes and the emergence of cerebrovascular causes in sub-Saharan Africa. Some epileptogenic lesions, such as certain brain tumors, focal cortical dysplasias, hippocampal sclerosis, have been under diagostized because of the poor availability and accessibility of cerebral MRI.

Keywords: Epilepsies etiologies; Brain; CT scan

\section{Introduction}

Epilepsy is a common disease in the tropics and especially in subSaharan Africa. Its incidence remains high in sub-Saharan Africa, ranging from 64 to $159 / 100,000$ inhabitants [1,2]. Its prevalence is 2 or 3 times higher than that found in the industrialized countries, in fact, extremely variable depending on the country and the study methodology used, with extremes of $5.2 \%$ to $74 \%$ and median evaluated at $15 \%$ [2]. A terminological and conceptual revision of the organization of epileptic seizures and epilepsies was adopted in 2010 [3]: non-genetic epilepsies (formerly called "non-idiopathic") now include epilepsies from structural, metabolic, infectious, immune (formerly "symptomatic epilepsies") or unknown cause (formerly "cryptogenic or probably symptomatic epilepsies"). In sub-Saharan Africa, there is a probable overestimation of generalized tonicclonic seizures (59\%), due to under-medicalization, the shortage of neurologists and electroencephalograms that could be the cause of 'poor seizure classification [2]; In contrast, there is an underestimation of the proportion of focal and then bilateral tonic-clonic seizures, whose focal point is difficult to recognize by the clinic alone. However for Senanayake and Roman [4], there would be a predominance of focal seizures and even lesional epilepsies, especially in Nigeria.

In developing countries in general and in sub-Saharan Africa in particular, the etiological diagnosis of epilepsies is most often based on interrogation and clinical examination, the routine complementary diagnostic means that are the electroencephalogram (EEG) and cerebral or specialized CT scans such as magnetic resonance imaging (MRI) with limited availability and accessibility [2]. Thus until 2006, epilepsies of unknown cause accounted for more than $50 \%$ of the cases in this part of the world, but this proportion tended to decrease according to the number of paraclinical explorations carried out, in particular neuroradiological. The causes identified are multiple, varying according to age and geographical location, reported in 20 to $50 \%$ of patients included in major epidemiological

*Corresponding author: Lompo Djingri Labodi, Tingandogo University Hospital, Health Sciences Research and Training Unit (UFR/SDS), Ouaga University I-Pr Joseph Ki-Zerbo, Toma, Burkina Faso, Tel: 226702398 34; E mail: labodilompo@yahoo.fr

Received January 27, 2018; Accepted February 10, 2018; Published February 15,2018

Citation: Labodi LD, Kadari C, Aziz DB, Ousseini D, Aida OS, et al. (2018) Etiologies of Non-Genetic Epilepsies of Adults Newly Diagnostic in Ouagadougou in Burkina Faso. J Neurol Disord 6: 375. doi:10.4172/2329-6895.1000375

Copyright: (c) 2018 Labodi LD, et al. This is an open-access article distributed under the terms of the Creative Commons Attribution License, which permits unrestricted use, distribution, and reproduction in any medium, provided the original author and source are credited. 
investigations [5]. Congenital, developmental and genetic causes are associated with epilepsy in childhood, adolescence and young adults. In the elderly, cerebrovascular causes are the most common. Head trauma, sporadic CNS infections and brain tumors occur at any age, although tumors appear to be more common beyond 40 years of age. The etiology of epilepsy may be multifactorial, and an acquired condition may be more likely to occur if hereditary predisposition is present [6]. It is difficult to determine the relative contributions of each cause of epilepsy in sub-Saharan Africa, even though infectious diseases, especially parasitic diseases such as cysticercosis or malaria, seem to be the most common causes $[2,7]$. In order to contribute to a better understanding of epilepsies in sub-Saharan Africa in general and in Burkina Faso in particular, we conducted the present descriptive cross-sectional study on etiological varieties of newly diagnosed adult non-genetic epilepsies in Ouagadougou, based on diagnostic, clinical, EEG and neuroradiological specific criteria (brain CT and/or MRI).

\section{Patients and Methods}

This was a prospective, cross-sectional, descriptive study that took place from September 1 to August 31, 2017, involving newly diagnosed patients with newly diagnosed non-genetic epilepsy at one of three sites the study in the city of Ouagadougou, with external consultation of neurology with recruitment of epileptic patients, Tingandogo University Hospital, Yalgado Ouedraogo Teaching Hospital and Schiphra Medical Center. Included in the study were all patients, at least 18 years old, who were neurologically outpatient in one of the 3 centers during our study period, in whom non-genetic epilepsy was diagnosed on the clinical, electroencephalographic and neuroradiological arguments (brain CT and/or MRI), having given their consent to their participation in the study.

For each patient collected, the following variables were studied: socio-demographic variables (age, sex, risk factors for epilepsy, level of education); clinical variables (age at onset of seizures, duration of seizures, frequency of seizures, seizure type according to Crisis classification and epilepsy of LICE 2010, neurological abnormalities, cognitive disorders, behavioral disorders), results of the EEG standard, results of encephalic imaging (CT and brain MRI), etiologies of epilepsy according to the 2010 LICE classification. For each patient collected an individual collection card was used. Data entry and analysis was done using the statistical software EPI INFO 7.1.10. The chi-square test and the Fischer test served as statistical tests with a significance level of $5 \%$. Patient confidentiality has been respected. The study was carried out with the authorization of the general direction of the various health structures and the bioethics committee of Burkina Faso.

\section{Operational definitions}

The diagnosis of epilepsy of non-genetic causes in adults was based primarily on the absence of arguments in favor of a genetic epileptic syndrome (formerly idiopathic): onset in children between the age of 4-10 years, the possibility of genetic epilepsy in family history but the absence of acquired risk factors for epilepsy in personal history, a neurological, neuroradiological and neuropsychological assessment normal, rare and brief crises often appear in sleep and $\mathrm{d}$ other, interictal paroxysmal abnormalities appearing on normal background activity, an increase in these abnormalities in sleep and an evolution most often favorable with healing towards puberty.

The diagnosis of epilepsies of structural cause was based on a bundle of arguments associating:
- The presence of risk factors for epilepsy, except genetic, in the patient's history,

- A beginning of epilepsy at all the ages of the life, a semiology including all the types of possible crises, - The frequent coexistence of neurological signs of focusing, cognitive deterioration, behavioral disorders and sometimes extra neurological signs suggesting an underlying disease responsible for epilepsy,

- Inter-critical EEG patterns suggestive of underlying brain damage: abnormal background activity, slow or asymmetrical; continuous slow waves, associated or not with spikes, spikes waves or polypoints waves; flattening focused along a focal point; independent multifocal abnormalities, diffuse paroxysmal abnormalities with predominantly anterior, predominantly anterior, predominantly anteriorly sloping spike type, showing the appearance of secondary bilateral synchrony [8]; reduction or disappearance of focal critical inter-axial anomalies before the first clinical signs appear, polymorphic critical discharge, the existence of slow rhythmic waves, critical discharges without clinical translation.

- Neuroimaging of a fixed or progressive structural lesion, whose epileptogenicity has already been demonstrated, with a positive anatomo-electro-clinical correlation [8].

The epilepsies of unknown cause (formerly cryptogenic) were based on the same diagnostic criteria, clinical and EEG, as the epilepsies of structural causes, but differed in the negativity of the neuroradiological examinations, notably the absence of causal lesions at the cerebral CT for all our patients and at the encephalic MRI for some. In addition to the diagnostic criteria, epilepsies related to a structural or metabolic cause have been diagnosed by CT or MRI visualization of structural abnormalities for which the existence of an association has been demonstrated with a substantial increase in the risk of developing epilepsy through rigorous studies. These cicatricial lesions, acute or progressive, include stroke, head trauma, infections, brain tumors, pre-perinatal encephalopathy sequelae, certain neuroectodermal diseases, miscellaneous malformations of cortical development, chronic alcoholism. The metabolic causes were not explored in our study, for reasons of financial inaccessibility or unavailability of these tests for our patients.

\section{Results}

During our study period we collected a total of 137 patients. The mean age of the patients was $41.8 \pm 17.6$ years (range 18 to 86 years), there were 71 male patients (51.8\%) and 66 female patients (48.2\%), which is a sex ratio $\mathrm{M} / \mathrm{F}$ of 1.07 . The age groups between 15 and 45 years were the most represented. One hundred (100) patients (73\%) were still in school or had completed at least secondary education, 27 patients (20\%) had never been to school and 10 patients (7\%) had dropped out of primary school. Of the 110 patients initially enrolled, 34 (30.9\%) had a primary level, $43(39.1 \%)$ a secondary level and $33(30 \%)$ a higher level. At least one epileptic FR was identified in the history of 81 patients or $59.1 \%$; the most frequently reported were head trauma in 15 patients $(10.9 \%)$, stroke and cerebral infectious disease in 22 patients (16.1\%) each The average age of onset of the first seizures was 34.3 years \pm 19.1 (range 1 to 83 years), the age range of onset of seizures between 15 and 45 years was the most representative, or $79 \%$ of patients. The average duration of seizures to diagnosis was 7.3 years per patient (range 1 to 49 years). The most frequent periodicity was daily in 48 patients (35\%) and monthly in 56 patients (40.5\%). Of the 137 patients, $120(87.50 \%)$ had a focal seizure, 7 patients $(5.20 \%)$ had a generalized crisis and 10 patients (7.30\%) had non-classifiable seizures. Among the 120 cases of focal seizures: 100 patients or $83.3 \%$ had a focal seizure 
Citation: Labodi LD, Kadari C, Aziz DB, Ousseini D, Aida OS, et al. (2018) Etiologies of Non-Genetic Epilepsies of Adults Newly Diagnostic in Ouagadougou in Burkina Faso. J Neurol Disord 6: 375. doi:10.4172/2329-6895.1000375

Page 3 of 6

without impaired consciousness. Of these 100 cases of CF without impaired consciousness, 95\% progressed to convulsive bilateralisation; 20 patients $(16.6 \%)$ had a focal seizure with impaired consciousness of which 18 cases (15\%) with psychomotor automatisms. Cognitive deterioration with 63 cases (46\%), focused motor deficit with 34 cases (24.8\%), behavioral disorders with 26 cases (19\%), focused sensory deficit with 13 cases $(9.5 \%)$ and the various other neurological disorders with 18 cases (13.1\%), were the main neurological and neuropsychic associated signs.

Of the 137 patients, all had an EEG and a brain scan, only 16 patients $(11.8 \%)$ were able to achieve more encephalic MRI. Standard EEG was normal in 18 patients (13.1\%); there were inter-critical epileptic paroxysms in 119 patients (86.9\%). Frontal epileptic paroxysms with 42 cases $(30.7 \%)$, plurifocal or diffuse paroxysms with 40 cases $(29.2 \%)$ and temporal paroxysms with 13 cases $(9.5 \%)$ were the most representative. Background activity was abnormal in 121 cases (93.8\%); they were slow theta waves (93.4\%), slow delta waves (4.1\%), and fast rhythms (2.5\%). The results of the neuroradiological examinations, CT or brain MRI were abnormal in 74 cases (54\%). Non-specific brain atrophy with 61 cases or $44.5 \%$, stroke sequelae with 22 cases (16.1\%), and porencephalic cavities with 16 cases (11.8\%) were the most frequently encountered neuroradiological abnormalities. At least one etiology of epilepsy was identified in 74 patients, $54 \%$; in 63 patients, $46 \%$, no cause was identified. Central nervous system (CNS) infections with 23 cases (16.8\%), stroke sequelae with 22 cases (16\%) and sequelae of head trauma with 15 cases (10.9\%), were the causes most frequently reported epilepsy. Among CNS infections, there were 10 cases of meningoencephalitis sequelae (7.3\%), 6 cases of neurocysticercosis (4.4\%), 5 cases of cerebral toxoplasmosis (3.6\%) and 2 cases of brain abscess (1.5\%). As for the 12 cases of brain tumors they were divided into 7 cases of astrocytoma, 4 cases of meningioma and 1 case of DNET. Regarding cerebral vascular malformations, 2 cases of cavernoma were identified (Table 1).

\begin{tabular}{|c|c|c|}
\hline Variables & Numbers & Frequencies \\
\hline \multicolumn{3}{|l|}{ Risk factors for epilepsy in antecedents } \\
\hline Head trauma & 15 & $10.9 \%$ \\
\hline AVC & 18 & $13.1 \%$ \\
\hline $\begin{array}{l}\text { Infectious encephalic } \\
\text { pathology (non-specific } \\
\text { meningoencephalitis, toxoplasmosis. } \\
\text { neurocysticercosis) }\end{array}$ & 22 & $16.1 \%$ \\
\hline Perinatal encephalopathy & 7 & $5.1 \%$ \\
\hline Brain tumor already known & 7 & $5.1 \%$ \\
\hline Febrile seizures & 2 & $1.5 \%$ \\
\hline \multicolumn{3}{|l|}{ Periodicity of seizures } \\
\hline Daily seizures & 48 & $35 \%$ \\
\hline Weekly seizures & 15 & $10.9 \%$ \\
\hline Monthly seizures & 56 & $40.5 \%$ \\
\hline Quartely seizures & 9 & $6.6 \%$ \\
\hline Half-yearly seizures & 5 & $3.6 \%$ \\
\hline Annual seizures & 4 & $1.6 \%$ \\
\hline \multicolumn{3}{|l|}{ Type of seizures } \\
\hline Focales seizures & 120 & $87.5 \%$ \\
\hline $\begin{array}{l}\text { Focal motor seizures without impaired } \\
\text { consciousness }\end{array}$ & 74 & $54.0 \%$ \\
\hline $\begin{array}{l}\text { Focal seizures with subjective sensory } \\
\text { phenomena }\end{array}$ & 40 & $29.2 \%$ \\
\hline - $\quad$ Focal seizures with psychic phenomena & 25 & $18.2 \%$ \\
\hline $\begin{array}{l}\text { Focal seizures with dysautonomic signs } \\
\text { without impared consciousness }\end{array}$ & 20 & $14.6 \%$ \\
\hline $\begin{array}{l}\text { Focal seizures with impaired consciousness } \\
\text { with or without psychomotor automatisms }\end{array}$ & 20 & $14.6 \%$ \\
\hline
\end{tabular}

\begin{tabular}{|c|c|c|}
\hline Generalized seizures & 7 & $5.2 \%$ \\
\hline Unclassifiable seizures & 10 & $7.3 \%$ \\
\hline \multicolumn{3}{|l|}{ Topography of epileptic paroxysms } \\
\hline Frontal paroxysms & 42 & $30.7 \%$ \\
\hline Temporal paroxysms & 13 & $9.5 \%$ \\
\hline Central paroxysms & 5 & $3.6 \%$ \\
\hline Pariétal paroxysms & 9 & $6.6 \%$ \\
\hline Occipital paroxysms & 3 & $2.2 \%$ \\
\hline Generalized paroxysms & 7 & $5.1 \%$ \\
\hline Mulfifocal or diffuse paroxysms & 40 & $29.2 \%$ \\
\hline Normal EEG & 18 & $13.1 \%$ \\
\hline \multicolumn{3}{|l|}{ Neuroradiological abnormalities } \\
\hline Cortico-subcortical atrophy & 61 & $44.5 \%$ \\
\hline $\begin{array}{l}\text { Localized atrophy associated with } \\
\text { adjacent cerebral parenchymal } \\
\text { hypodensity }\end{array}$ & 48 & $35 \%$ \\
\hline $\begin{array}{l}\text { Hemi hemispherical atrophy associated } \\
\text { with ipsilateral thickening of the cranial } \\
\text { vault, ipsilateral dilation of the sinuses } \\
\text { of the base. ascent of the rocks }\end{array}$ & 4 & $2.9 \%$ \\
\hline Cerebral diffuse atrophy & 9 & $6.7 \%$ \\
\hline Periventricualar leuko encephalomalacy & 3 & $2.2 \%$ \\
\hline Porencephalic cavity & 16 & $11.8 \%$ \\
\hline $\begin{array}{l}\text { Peripheral cortico-subcortical hypodensities } \\
\text { without CT contrast enhancement }\end{array}$ & 14 & $10.2 \%$ \\
\hline Cerebral tumors & 12 & $8.8 \%$ \\
\hline - Astrocytoma & 7 & $5.1 \%$ \\
\hline - Méningioma & 4 & $2.9 \%$ \\
\hline DNET & 1 & $0.7 \%$ \\
\hline $\begin{array}{l}\text { Multifocal cortico-subcortical nodular brain } \\
\text { calcifications }\end{array}$ & 9 & $6.7 \%$ \\
\hline $\begin{array}{l}\text { Inflammatory granulomas or cerebral } \\
\text { abscesses }\end{array}$ & 7 & $5.1 \%$ \\
\hline $\begin{array}{l}\text { Neurocysticercosis nodular granular or } \\
\text { calcified nodular stages }\end{array}$ & 6 & $4.4 \%$ \\
\hline Hippocampic sclerosis at RMI & 2 & $1.5 \%$ \\
\hline Cerebral cavernoma at MRI & 2 & $1.5 \%$ \\
\hline \multicolumn{3}{|l|}{ Etiologies of epilepsies } \\
\hline Structural causes identified & 74 & $54 \%$ \\
\hline Sequelaes of cranial trauma & 15 & $10.9 \%$ \\
\hline Infections of CNS & 23 & $16.8 \%$ \\
\hline - Sequelaes of stroke & 16 & $11.7 \%$ \\
\hline Cerebral tumors & 12 & $8.7 \%$ \\
\hline Sequelaes of perinatal encephalopathy & 4 & $3 \%$ \\
\hline Hippocampic sclerosis & 2 & $1.5 \%$ \\
\hline $\begin{array}{l}\text { Vascular cerebral malformations: } \\
\text { cavernoma }\end{array}$ & 2 & $1.5 \%$ \\
\hline Causes Unknown causes or undetermined & 63 & $46 \%$ \\
\hline
\end{tabular}

Table 1: The results of the neuroradiological examinations.

\section{Discussion}

The mean age of patients at inclusion in this study was 41.8 years, the average age of onset of first seizures of 34.4 years and age groups 15-45 years higher rate of epileptic patients. Our results are similar to those of other studies in sub-Saharan Africa $[2,9,10]$. However our results differ from those of European and US studies, where epilepsy has a bimodal distribution, marked by a high prevalence at both extremes of life, before the age of 5 years and after the age of 60 [11]. This difference could be explained by the demographic characteristics of the developing countries to which Burkina Faso belongs: high birth rates and low life expectancy, particularly the lower survival of elderly people with head trauma, stroke or neoplasm. The consequences are a significant proportion of people under 15 and a low representation of the over 50 s (6.9\% to $15.1 \%$ of the population) [12]. 
Almost all epilepsy studies around the world, including in developing countries $[2,10,13,14]$ as in the industrialized countries [11], find a male predominance. The same observation was made in our study. This difference in frequency could be explained in sub-Saharan Africa by the social impact of epilepsy, since girls of marriageable age tend to hide their epilepsy. The hypothesis of an association between the masculine gender and the risk of occurrence of epilepsy also deserves to be explored [2]. A predominance of women has already been reported in Nigerian [2], Egyptian [15] and Ecuadorian studies [16]; the hypothesis of a rural exodus of men or that of a higher male mortality has been advanced to explain this finding. In our series we found a predominance of focal seizures in a proportion of $87.5 \%$, just like the Senanayake et al. series in Nigeria [4], Kuaté et al. [14]. Our results are consistent with European studies of adults and the elderly, who experience focal seizures/epilepsies in $55-83 \%$ of cases, initially generalized seizures in $6-32 \%$ and seizures not classified in 8 at $20 \%$ [11]. These results, however, differ from most studies in sub-Saharan Africa, which report a predominance of generalized tonic-clonic seizures (on average $59 \% \pm 21 \%$ ) $[2,10,17]$. This can be explained by methodological differences such as the non-inclusion of genetic epilepsies in our study, by under-medicalization and more particularly by the insufficient number of neurologists and EEG devices that do not allow a relevant classification of epileptic seizures, in most studies in sub-Saharan Africa.

In our series, head trauma was the third leading cause of nongenetic epilepsy in adults, with a proportion of $10.9 \%$, confirming the high frequency of this etiology in epilepsies in sub-Saharan Africa. Indeed, in most African series, an antecedent of head trauma was found on average in $8 \%( \pm 5)$ of all epileptic patients versus $11.4 \%$ to $14.5 \%$ of epilepsies of structural or metabolic causes in China [18] and 5\% of all epilepsies in industrialized countries (2-16\% extremes) [11,17,19], an even lower rate of $1.7 \%$ reported in India [19]. Road accidents, which are common in Africa due to the lack of traffic regulation, the obsolescence of the road network, the absence of seatbelt use or the helmet for motorcyclists, are the main causes of head trauma. Head injuries can also be caused by workplace accidents, aggression or injuries during wars or violent sports. The high proportion of post-traumatic etiology in our series is due to the specificity of our study population, which focused only on non-genetic epilepsies in adults, whereas in most studies, the study population usually covers all epilepsies in children and adults, including presumed genetic epilepsies. Post-traumatic epilepsy results mainly from sequelae of brain contusions after a free interval usually less than 2 years. The risk of crisis increases with the severity of the trauma and the immediate brain lesions but also with the topography of the initial lesion: the sequelae of parietal contusions are the most epileptogenic [20]. The most severe sequelae of cerebral contusion appear on CT in the form of cerebral atrophy associated with hypodensity of the adjacent cerebral tissue. These lesions predominate in the frontal lobe; the rarer parietoocipital localizations sometimes result in backache lesions. The use of MRI indicated in CT failures, allows a complete lesion balance thanks to the sequence FLAIR which visualizes the cortical atrophy and the adjacent parenchymatous lesions in the form of a hypersignal which translates a gliosis and a demyelination. The gradient echo T2 sequence identifies the hemorrhagic sequelae as cortical and sub-cortical hypo signal foci in the sus tentorial white matter and the corpus callosum [21]. In our series, all diagnoses of post-traumatic brain injury were confirmed by cerebral CT; no post traumatic cerebral lesion was supported by brain MRI, even with negativity of cerebral CT. This may have contributed to underestimating the proportion of this etiological category in our study.
In our series, brain tumors accounted for $8.7 \%$ of non-genetic epilepsy causes in adults, whereas this etiology averaged only $3 \%( \pm 3)$ of all epilepsies in all age groups in sub-Saharan African series [2,14,17] Methodological differences can explain this difference, especially study populations. The respective rates of $3.6 \%$ and $6.9 \%$ of all structural and metabolic epilepsies have been reported in India [20] and China [18]. In western countries, tumor etiology is found on average in $8 \%$ $(10-20 \%)$ of all epilepsies in children and adults $[6,11,22]$. The undermedicalization, the low availability and sometimes the financial inaccessibility of cerebral CT exams and especially the unavailability of MRI machines in sub-Saharan Africa, examinations which are nevertheless essential for the diagnosis of brain tumors, can in fact skew the magnitude of brain tumors within epilepsy causes in this part of the world [23]. CT recognizes most epileptogenic tumors; only a few temporal tumors or isodense tumors escape this examination [22]. The sensitivity of MRI is close to $100 \%$, but some glioblastomas may go undetected [24]. In our series, epileptogenic brain tumors were dominated by low grade astrocytomas and meningiomas. Indeed, the epileptogenicity of tumors depending on their natures: tumors of slow evolution, with little or no neurological signs of focusing during a long period of their evolution, such as low-grade gliomas, gangliogliomas, DNETs, meningiomas are epileptogenic in 60 to $85 \%$ of cases, compared with 20 to $40 \%$ for high-grade brain tumors and 15 to $20 \%$ for brain metastases $[2,25,26]$. Epileptogenicity also depends on the tumor localization: the cortical situations, the temporal cortical topographies or the primary sensorimotor cortex or the additional motor area, seem to be the most likely to give rise to epileptic seizures.

CNS infections were found in $16.8 \%$ of our patients and were the leading cause of non-genetic epilepsy in adults. They were divided into sequelae lesions and infectious lesions still evolving. The sequelae lesions of meningoencephalitis (8\%) were found on cerebral CT in the form of localized cortico-subcortical atrophy, associated with non-contrasting adjacent parenchymal cerebral hypodensity, indicative of sequelae of gliosis and demyelination. The sequelae lesions of neurocysticercosis (4.4\%) were visualized at the calcified and granular nodular stage. The sequelae of toxoplasmic abscess (4.4\%) presented on CT as localized hypodensity without enhancement sometimes associated with calcification. With regard to progressive infectious lesions, they consisted mainly of pyogenic, tuberculous and toxoplasmic cerebral abscesses. Infectious aetiologies are suspected on average in $9 \%( \pm 7 \%)$ of cases in the tropics, possibly as much as $20 \%$ to $26 \%$ of all epilepsies usually reported in sub-Saharan Africa, from all causes $[2,4,10]$. The proportion of epilepsies from infectious causes in epilepsies from lesional causes was $25 \%$ in adults in a Chinese hospital series [18], whereas it was $17.4 \%$ in India [20]. These results are well above the average of $1.25 \%$ $(0-2 \%)$ reported by the European series [11]. These differences could be explained by the fact that infectious diseases that can lead to epileptic manifestations are much more numerous in the tropics, due to the specificities of tropical ecosystems, the insufficiency, or the absence of the campaigns of vaccinations as well as delays or failure to take appropriate care $[1,2,4,12]$. Among these infectious causes, the most frequent are the meningo-encephalitis virales particularly measles and HIV, the meningo-encephalitis bacterial, in particular with meningococcus, with $\mathrm{BK}$, including the intracranial tuberculomes [2,27]. As for parasitic infections, they seem to be dominated by neurocysticercosis reported in 5 to $50 \%$ of the causes of epilepsy in sub-Saharan Africa [1,2]; history of malarial infection with Plasmodium falciparum $[28,29]$, toxoplasmosis, schistosomiasis, and toxocariasis [27]. The main predictors of postinfection CNS epileptogenicity are: the occurrence of epileptic status in the acute phase, the infectious agent, the severity of the cerebral parenchymal lesion [30]. 
In our study, stroke was the second leading cause of non-genetic epilepsy, at $11.7 \%$. This result falls within a wide range of post-stroke epilepsy rates in sub-Saharan Africa, ranging from $1 \%$ to $42 \%$, with an average of $7 \%( \pm 10 \%)$. However, our results seem to be lower than those found in industrialized and emerging countries, where an average of $17.5 \%(14-21 \%)$ [11] and $26.4 \%$ [20] of epileptic patients, respectively, have a post stroke etiology. The methodological differences in the African series, some with mandatory neuroimaging, the others without neuroimaging based solely on interrogation and clinical examination, and finally the inclusion or not of genetic epilepsies, explain these wide variations observed. However, around the world, post-stroke epilepsy appears to be the preserve of the elderly, and stroke sequelae appear to be the leading cause of epilepsy after age $50[2,20,31]$. Perinatal causes accounted for $3.6 \%$ of cases in our study, a proportion lower than the $9 \% \pm 8 \%$ average reported in the African literature [2]; this difference could be explained by methodological differences, because for most African series, the diagnosis of perinatal causes is often based on the only interrogation of the patient, or possibly of the entourage, and thus subject to memorization biases. But it is also possible that some patients, particularly those with severe disease, did not survive to adulthood. In our series, in addition to a history of perinatal encephalopathy, patients had to have compatible brain imaging. Rates of $8.9 \%$ were found in India [20]. Perinatal causes are probably major in Africa because of numerous home births, without skilled help, or difficult deliveries in under-equipped environments [32], causing frequent obstetric trauma, anoxia or cerebral ischemia, aggravated by associated factors such as multiparity, prematurity, anemia, malnutrition, maternal infections [4]. Sequelae of hypoxia-neonatal anoxia are responsible for leukoencephalomalacia and cortical atrophy lesions; clinically mental retardation is associated with epilepsy in $50 \%$. Sequelae of neonatal hypoglycaemia are responsible for bilateral occipital cortical atrophy associated with sub-cortical white matter hypodense and posterior corpus callosal atrophy. Sequelae of stroke or antenatal infection result in porencephalic cavities. Infant cerebral hemiplegia results in a cortico-subcortical cerebral hemisphere associated with ipsilateral thickening of the cranial vault. Such lesions were found in our study.

Epileptogenic cerebral vascular malformations are represented by $1 / 3$ of arteriovenous malformations, $45 \%$ of cavernous angiomas and giant arterial aneurysms compressing the cerebral parenchyma [22]. In our series, we identified 2 cases of cavernous angioma, within epileptogenic cerebral vascular malformations. In our study, hippocampal sclerosis accounted for $1.5 \%$ of the causes of non-genetic epilepsy in adults, while it accounts for up to $65 \%$ of cases in surgical series [22,26]. This is due to the low use of MRI (11\%) by our patients, the only exam able to diagnose this lesion. Some causes of epilepsy reported in the literature, especially Western, have not been found in our study; these are: alcoholic epilepsy sometimes representing up to 12 to $25 \%$ of the lesional or metabolic causes of epilepsies [33] and found in 1 to $7 \%$ (5\% on average) of epileptic patients in sub-Saharan Africa [2], neurodegenerative diseases dominated in particular Alzheimer's disease and vascular dementia, described in 1 to $5 \%$, systemic diseases such as systemic lupus erythematosus and vasculitis of the CNS, mitochondrial diseases, This could be explained by differences socio-cultural, low life expectancy in our context, the inaccessibility and/or unavailability of some methods of neuroradiological explorations such as MRI, the exams of autoimmunity, Epilepsies from unknown causes were found in $46 \%$ of patients in our series, whereas in most series in sub-Saharan Africa this category accounted for more than $50 \%$ of investigations (on average $50 \%$ \pm 26 ), especially for series whose etiological diagnosis was based solely on interrogation and clinical examination. This proportion decreased as a function of the neuroradiological explorations carried out, CT and/or encephalic MRI $[2,14,17]$. In this type of epilepsy, a cause is presumed, but the current diagnostic means do not make it possible to highlight it [2]. Thus in developed countries where sophisticated neuroradiological explorations (spiral CT, high resolution morphological MRI combined with metabolic and functional techniques, PET) are available and accessible to all epileptics, the rate of unknown causes falls to about $20 \%$ of the all epilepsies of the adult and the child $[34,35]$.

\section{Limits and peculiarities of our study}

Unlike most studies in sub-Saharan Africa, our study was limited to adult patients over the age of 18 years, with epilepsy of non-genetic cause, excluding the children and adolescent's population and the epilepsy population presumed genetic cause. Some causes of epilepsy, including perinatal events, some CNS infections, some head trauma, found during the interrogation in the antecedents, could not finally be retained, because of a lack of obvious lesion on cerebral CT, helping to overstimate the proportion of unknown causes.

The low achievement rate of brain MRI yet recognized as gold standard for the etiological diagnosis of structural cause epilepsy, probably contributed to overestimate the proportion of unknown causes and underestimated structural causes. The metabolic causes were not sought in our study, because of the additional cost that their explorations would weigh on our epileptic patients, often deprived.

\section{Conclusion}

Non-genetic epilepsies in adults in Ouagadougou (Burkina Faso) classified etiologically according to clinical, EEG and neuroradiological criteria. All patients underwent clinical examination, standard EEG, brain CT, but only $11.5 \%$ were able to perform brain MRI. No patient was able to perform specialized biological examinations; the metabolic causes could not therefore be sought. The structural causes and unknown causes were found respectively in 54\% and in $46 \%$ of cases. CNS infections (16.8\%), sequelae of stroke (11.7\%), sequelae of cranioencephalic trauma $(10.9 \%)$, brain tumors $(8.7 \%)$, sequelae of perinatal encephalopathy (4\%) and cerebral vascular malformations (cavernoma) (1.5\%) were the epileptogenic structural abnormalities found. Our results confirm the predominance of infectious and posttraumatic causes and the emergence of cerebrovascular causes in subSaharan Africa. Certain epileptogenic lesions, such as certain brain tumors, focal cortical dysplasias, hippocampal sclerosis, etc., have been underdiagosed because of the poor availability and accessibility of cerebral MRI. Other causes such as alcoholic epilepsy, neurodegenerative diseases, systemic diseases, mitochondrial diseases, have probably not been diagnosed because of the unavailability of some expensive biological explorations such as the autoimmunity balance Increased availability and accessibility of neuroimaging examinations, particularly brain MRI and some sophisticated biological investigations, would contribute to a better etiological diagnosis of non-genetic epilepsy in adults.

\section{References}

1. Druet-Cabanac M (2002) Prévalence de l'épilepsie en Afrique sub-saharienne. Epilepsie 134-136.

2. Ngoungou EB, Quet F, Dubreuil CM, Marin B, Houinato D, et al. (2006) Épidémiologie de l'épilepsie en Afrique subscribe: au revue de la literature Cahiers Santé 18: 25-40.

3. Berg AT, Berkovic SF, Brodie MJ, Buchhalter J, Cross H, et al. (2009) Rapport de la Commission de ILAE en la Terminale et Terminology 1-12.

4. Senanayake N, Roman GC (1993) Epidemiology of epilepsy in developing countries. Bull WHO 71: 247-258. 
Citation: Labodi LD, Kadari C, Aziz DB, Ousseini D, Aida OS, et al. (2018) Etiologies of Non-Genetic Epilepsies of Adults Newly Diagnostic in Ouagadougou in Burkina Faso. J Neurol Disord 6: 375. doi:10.4172/2329-6895.1000375

5. Adelow C, Andell E, Amark P, Andersson T, Hellebro E, et al. (2009) Newly diagnosed single unprovoked seizures and epilepsy in Stockholm, Sweden: First report from the Stockholm Incidence Registry of Epilepsy (SIRE). Epilepsi 50: 1094-1101.

6. Sander JWAS, Shorvon SD (1996) Epidemiology of the epilepsies. J Neurol Neurosurg Psychiatry 61:433-443.

7. (1994) Relationship between epilepsy and tropical diseases. Commission on tropical diseases of the International League Against Epilepsy. Epilepsia 35 89-93.

8. Kahane P, Arzimanoglou A, Bureau M, Roger J (2005) Non-idiopathic partial epilepsies of the child. In epileptic syndromes of children and adolescents pp: 255-274

9. Grunitzky EK, Dumas M, Mbella EM, Balogou A, Belo M, et al. (1991) Les épilepsies au Togo. Epilepsies 3: 295-303.

10. Napon C, Tamboura Y, Kabore J (2009) Epilepsies of more than 14 years patients in the university hospital of Ouagadougou. Epilepsy 21: 93-97.

11. Forsgren L, Beghi E, Oun A, Sillanpaa M (2005) The epidemiology of epilepsy in Europe - A systematic review. Eur J Neurol 12: 245-253.

12. Quet F, Odermatt $P$, Preux PM (2008) Challenges of epidemiological research on epilepsy in resource-poor countries. Neuroepidemiology 30: 3-5.

13. Debouverie M, Kabore J, Dumas M, Weber M, Duboz P, et al. (1993) Epidemiology of epilepsy in Burkina-Fasoln: Tropical Neurology 57-61.

14. Kuate D, Etoundi B, Azantsa BKG, Kengne AN, Ngondi JL, et al. (2010) The use of LeptiCore ${ }^{\circledR}$ in reducing fat gain and managing weight loss in patients with metabolic syndrome. Lipids Health Dis 9: 1-20.

15. El-Gengaihy ME, Wasif SM, Hamid FF, El-Shazli SM, Zitoum MA, et al. (1993) Epidemiological Study of Epilepsy in Egypt. Tropical neurology 39-45.

16. Barberis P, Cruz ME (1993) Epidemiology of epilepsy in Ecuador. Tropical Neurology pp: 35-38.

17. Doumbia M, Kouassi L, Diarra EK, Kouame-Aswan AE, Tanoh CA, et al. (2008) Contribution of cerebral computed tomography in the management of adult epilepsies in Ivory Coast. Epilepsy 4: 290-293.

18. Si Y, Liu L, Hu J, Mu J, Fang J, et al. (2012) Etiologic features of newly diagnosed epilepsy: hospital-based study of 892 consecutive patients in West China. Seizure 21: 40-44.

19. Hauser WA, Annegers JF, Kurland LT (1993) The incidence of epilepsy and unprovoked seizures in Rochester, Minnosota: 1935-1984. Epilepsia 34: 453-458.
20. Murthy JMK, Yangala R, Srinivas M (1998) The Syndromic Classification of the International League Against Epilepsy: A Hospital-Based Study from South India. Epilepsia 39: 48-54.

21. Dieteman JL, Mazzini L, Cossa FM, Angelino F, Campini R, et al. (2003) Post traumatic epilepy: neuroradiological and neuropsychologic assessment of long term-term outcome. Epilepsia 44: 569-574.

22. Dieteman JL, Chassagnon S, Cepreganov M (2012) Epilepsies: Neuro diagnostic imaging, (2nd edn), Paris, Elsevier, Masson, SAS

23. Loembe PM, Bongo Epaly GO, Ramarojoana R, Ompounga ML (1995) Tumor epilepsy in adults in Gabon: diagnostic problem and therapeutic attitude. Med Trop 55: 68-72.

24. Landy HJ, Lee TT, Potter P, Feun L, Markoe A, et al. (2000) Early MRI finding in high grade glioma. J Neurooncol 47: 65-72.

25. Charles J. Vecht C J, Van Breemen M (2006) Optimizing therapy of seizures in patients with brain tumors. Neurology 67: S10-S13.

26. Le reste PJ, Biraben A (2011) Etiologies des épilepsies. EMC, Neurologie 8 1-10.

27. Ramantani G, Holthausen $H$ (2017) Epilepsy after cerebral infection: review of the literature and the potential for surgery, Epileptic Disord 19: 117-136.

28. Carter JA, Neville BGR, White S, Ross AJ, Otieno G, et al. (2004) Increased prevalence of epilepsy associated with severe falciparum malaria in children Epilepsia 45: 978-81.

29. Ngoungou EB, Dulac O, Poudiougou B (2006) Cerebral malaria and epilepsy in a cohort of 322 Malian children. Epilepsia in press.

30. Lee WT, Yu TW, Chang WC, Shau WY (2007) Risk factors for postencephalitic epilepsy in children: a hospital-based study in Taiwan. Eur J Paediatr Neurol 11: 302-309.

31. Serre I (2009) AVC du sujet âgé et épilepsie. Épilepsies 21: 239-242.

32. Farnarier G, Guèye L (1998) Facteurs de risque particuliers des épilepsies en Afrique. Epilepsies 10: 105-114.

33. Santos S, Mauri JA, Lopez de val J, Tagero C, Morales S (1999) Symptomatic epilepsy, review of 208 patients. Rev Neurol 28: 846-845.

34. Kuzniecky RI (2004) Neuroimaging of epilepsy: Advances and pratical applications. Rev Neurol Dis 1: 179-189.

35. Urbach H (2005) Imaging of epilepsies. Eur Radiol 15: 494-500. 